\title{
Increased Lead Absorption Caused by Working Next to a Lead Recycling Factory
}

\author{
Kun-Yu Chao, MD, MPH, and Jung-Der Wang, MD, ScD
}

\begin{abstract}
The objective of this study was to determine whether workers at a factory in Taiwan, adjacent to lead recycling plant, were affected by lead contamination. Workers at the lead recycling plant itself were found to suffer from lead poisoning; air and soil outside the plant were heavily contaminated by lead. Forty-one of the 45 workers in a forging factory next to the lead recycling plant were enrolled as the exposed group. A comparison group of 51 workers were selected from another forging factory about $20 \mathrm{~km}$ away. Each subject was interviewed about his lifestyle, work history, and residence, and blood was drawn for lead measurement by graphite furnace atomic absorption spectrometry. The results showed that two groups were compatible in age, sex, and smoking patterns. Blood lead of the exposed group was significantly higher than that of the comparison group (mean \pm SD: $20.4 \pm 9.4 \mu \mathrm{g} / \mathrm{dl}$ vs. $5.9 \pm 2.9 \mu \mathrm{g} / \mathrm{dl}$ ). The difference was independent of sex and working zones. Blood lead levels were lower among exposed workers who had been employed less than 2 months compared with those employed longer. There was no difference among exposed workers in different outdoor working zones. Five months after improvement of pollution control and decrease in the production volume of the lead factory, 30 exposed workers were retested for blood lead. The blood lead of outdoor workers had an average decrease of $4.2 \mu \mathrm{g} / \mathrm{dl}$ while that of indoor workers showed no significant difference. We concluded that the changes of blood lead levels among exposed workers were caused by lead contamination generated by the neighboring lead recycling plant. (c) 1994 Wiley-Liss, Inc.
\end{abstract}

Key words: environmental contamination, community lead exposure, blood lead level, lead recycling factory

\section{INTRODUCTION}

Lead was first reported to be hazardous to health as early as 200 B.C. At the beginning of this century, Dr. Alice Hamilton [1943], the pioneer of occupational lead poisoning, reported that environmental lead pollution may cause health problems. Modern studies [De la Burde and Choate, 1972; Rutter, 1983; Lippmann, 1990; Rabinowitz et al., 1992] indicate that lead is not an essential element to man, and low levels of lead, e.g., $8-15 \mu \mathrm{g} / \mathrm{dl}$ in blood, may produce adverse effects in intellectual

Center for Research of Environmental and Occupational Diseases, Institute of Occupational Medicine and Industrial Hygiene, National Taiwan University College of Public Health, Taipei, Taiwan, Republic of China.

Address reprint requests to Dr. Jung-Der Wang, Institute of Occupational Medicine and Industrial Hygiene, National Taiwan University College of Public Health, No. 1, Section 1, Jen-Ai Road, Taipei, Taiwan, Republic of China 10018.

Accepted for publication August 4, 1993. 
development. Thus, prevention of lead poisoning should not be confined to the lead-related industries, but should be extended to the community [Freudenberg and Golub, 1987].

While there have been many reports about environmental pollution by leadrelated industries [Baker et al., 1977; Kaye et al., 1987; Wang et al., 1989; Vimpani et al., 1985; Baghurst et al., 1985; Morse et al., 1979], the victims were mostly confined to workers' families or residents, especially children, of nearby communities. The lead pollution in these outbreaks was spread by dust, fumes, or water. To our knowledge, few, if any, reports exist about the lead contamination spreading to nearby factories and workers.

In recent years, industrial development in Taiwan has been very rapid. The amount of lead utilization has been increasing and occupational lead poisoning is not uncommon [Soong et al., 1976; Yip et al., 1988; Jang and Wang, 1989]. In 1987, following a case of occupational poisoning in a lead battery recycling plant in northern Taiwan, we demonstrated that $85 \%$ of workers in the lead recycling plant had blood lead levels more than $40 \mu \mathrm{g} / \mathrm{dl}$ and $31.2 \%$ workers more than $80 \mu \mathrm{g} / \mathrm{dl}$. The average blood lead in office staff was up to $38.5 \mu \mathrm{g} / \mathrm{dl}$ [Jang and Wang, 1989].

Environmental monitoring demonstrated that air and soil outside the plant were contaminated by lead. The lead concentrations in the ambient air at distances of 50 and $100 \mathrm{~m}$ from the lead recycling plant were $12.9 \pm 11.4$ and $12.8 \pm 8.0 \mu \mathrm{g} / \mathrm{m}^{3}$, respectively, during sunny days, while they were lower-1/6 or $1 / 10$ - during rainy days [Wang et al., 1992]. The lead recycling plant is located in an industrial zone, and there is an iron forging factory nearby (Fig. 1). The objective of this study was to determine whether workers at the adjacent factory were affected by fugitive lead contamination.

\section{MATERIALS AND METHODS}

Forty-one out of 45 workers of a forging factory next to a lead recycling plant were enrolled as the exposed group; 30 of them voluntarily underwent follow-up examination 5 months later. The 86 workers from another forging factory, $20 \mathrm{~km}$ away with no lead-related factory nearby, were asked to be the reference group; 51 (59.3\%) voluntarily participated. These two forging factories had the same raw materials, manufacturing process, and products. Their raw materials contained no lead or its alloy. More than half of the workers of the exposed factory had worked in the reference factory, but they had left and set up their own company about 5 years previously. Thus, the operation of the two forging factories was comparable. After a walk through, we designed a questionnaire for this study, which contained basic demographic data, including sex, birthdate, work history, residence, transportation to and from the factory, jobs of family members, hobbies related to lead exposure, smoking, etc. Each subject was interviewed by four research assistants using standardized protocol. We defined those who stayed indoors more than half of their working time as working indoors, e.g., office staff, cook, guards, sanitary workers. Those who stayed in the semi-open plant more than half of their working time were defined as working outdoors, e.g., die making, steel cutting, forging, sand blasting, packing, quality control, and maintenance. Besides ventilation and dust exposure, the indoor and outdoor workers had different quantities and sources of drinking water. Since a smoker usually has a greater likelihood to inhale or ingest lead from a 

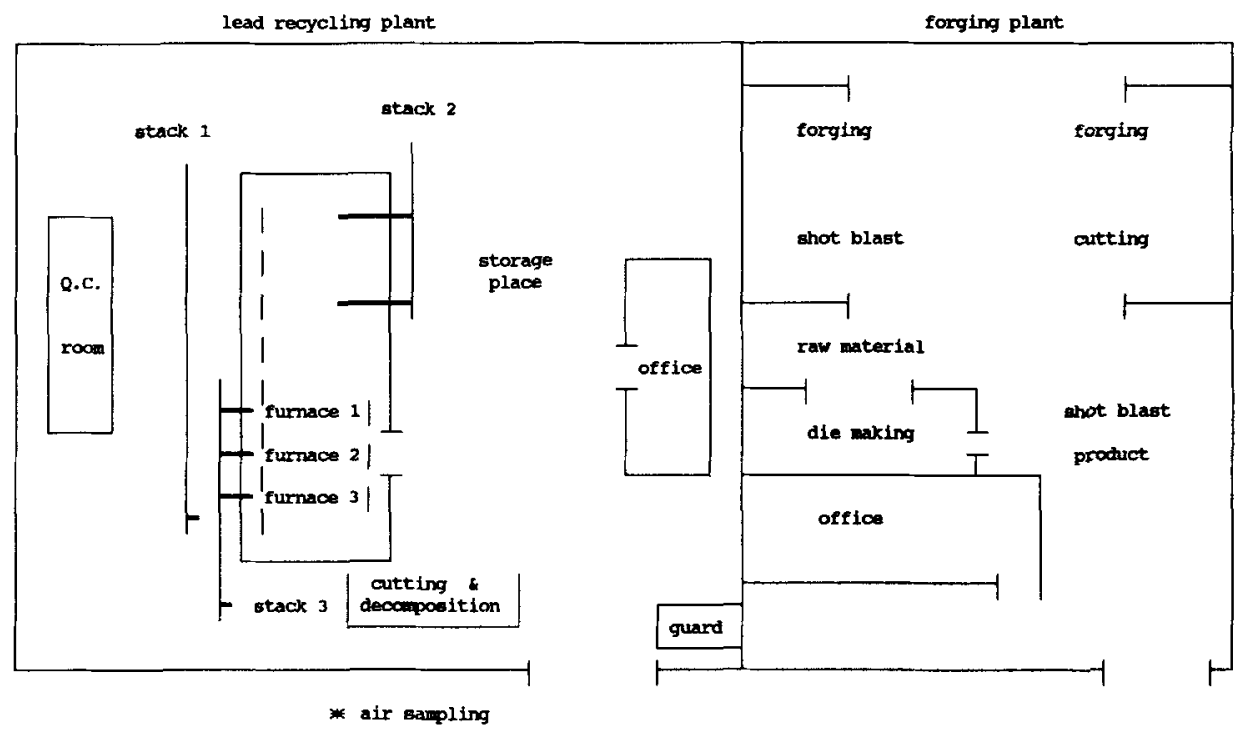

Fig. 1. Forging plant next to a lead recycling plant.

lead-contaminated workplace [Tola and Nordman, 1977], we defined those who had not abstained from smoking over the past 2 months and smoked more than one cigarette inside the plant each day as smokers.

All workers were asked to wash their antecubital area with soap and water first, and then each of them underwent venipuncture to collect $5 \mathrm{ml}$ venous blood with a vacuum tube (Monoject, Sherwood Medical, USA) containing ethylenediamine tetraacetic acid as the anticoagulant. Sample pretreatment was performed under a highefficiency particulate air filter (class 100). One hundred microliters of shaken blood sample was first added with $400 \mu \mathrm{l}$ of pretreatment solution containing $0.1 \%$ Triton $\mathrm{X}-100$ (scintillation grade) and $1.25 \%$ ammonium dihydrogen phosphate (puratonic grade). After homogenization, it was directly introduced into a Perkin-Elmer Zeeman 5100 pc through AS 60 autosampler for flameless atomic absorption spectrometry. Our laboratory has a consistent intralaboratory quality control and has participated in the blood lead proficiency test of the United States Centers for Disease Control (CDC) since 1985 . The average difference $( \pm 1 \mathrm{SD})$ of blood lead between our measurements and the CDC target values of 24 samples during 8 recent months was $1 \pm 1 \mu \mathrm{g} / \mathrm{dl}$, indicating that our blood lead measurements are accurate.

\section{Data Analysis}

Since the blood lead level is an indicator of lead exposure over the past 2-3 months [Zielhuis, 1983] we defined those who worked for less than 2 months as new workers. During data analysis, the new workers and three truck drivers who were usually working off-site and had relatively little lead exposure were grouped into a separate category.

Because our subjects were few in number and the blood lead distribution was not normal, most of the comparisons were performed using nonparametric methods, such as Wilcoxon rank sum test. For the comparison of the blood lead levels between 
TABLE I. Exposure Categories of Workers in Two Taiwanese Iron Forging Factories

\begin{tabular}{lcc}
\hline & $\begin{array}{c}\text { Exposed factory } \\
\text { next to lead } \\
\text { recycling plant }\end{array}$ & $\begin{array}{c}\text { Reference factory } \\
20 \mathrm{~km} \text { distant }\end{array}$ \\
\hline Total no. of workers & 45 & 86 \\
No. of examined workers & $41(91.1 \%)$ & $51(59.3 \%)$ \\
No. of new employees, and truck drivers & 5 & 4 \\
No. working indoors & 11 & 11 \\
No. working outdoors & 25 & 36 \\
\hline
\end{tabular}

the initial examination and 5 months later among the 30 workers at the exposed factory, a paired t test was used. Multiple linear regression analysis was also performed to determine significant risk factors for the initial blood lead. The independent variables included working indoors or outdoors at the exposed factory, sex, and smoking. A similar multivariate analysis was performed for the decrease in blood lead levels among workers at the exposed factory. The change in blood lead levels between the two examinations was the dependent variable; working indoors or outdoors, sex, and smoker were the independent variables. A p value of 0.05 was considered statistically significant.

\section{RESULTS}

We classified the subjects by exposure categories and factories (Table I). After excluding new employees and truck drivers the two groups were not different and relatively compatible for age, sex, and percentage of male smokers (Table II). None of female workers had ever smoked.

The average blood lead of the exposed group was significantly higher than that of the reference group (mean \pm SD: $20.4 \pm 9.4 \mu \mathrm{g} / \mathrm{dl}$ vs. $5.9 \pm 2.9 \mu \mathrm{g} / \mathrm{dl}$ ). This difference persisted after stratification by sex and working indoors vs. outdoors (Table III). Blood lead levels were lower among exposed workers who were employed for less than 2 months than those employed longer, but no such difference was observed in the reference group. There was no difference in blood lead among exposed workers who worked outdoors, according to their residence area (urban vs. rural), or according to their manufacturing job. Blood lead levels were higher among outdoor workers than among indoor workers at the exposed factory. This difference persisted even after stratification by gender. At the reference factory, the blood lead levels were the same among outdoor and indoor workers, regardless of sex. Multiple linear regression showed that blood lead was significantly associated with working at the exposed factory outdoors and indoors (Table IV).

In this study, all workers at the reference factory lived near their plant, which was located in a rural area. Twenty workers from the exposed factory lived in the same village. While 2 additional workers lived in the countryside, all the other 14 workers $(38.8 \%)$ of the exposed factory lived in a city or near a suburban area. Most cases of elevated blood lead (more than $15 \mu \mathrm{g} / \mathrm{dl}$ ) occurred among outdoor workers at the exposed factory. If we stratified them by residence as rural vs. urban, there was no difference in their blood lead. Also our survey found that none of workers had a 
TABLE II. General Characteristics of Examined Iron Forging Factory Workers Excluding New Employees and Truck Drivers

\begin{tabular}{lcc}
\hline & $\begin{array}{c}\text { Exposed factory } \\
\text { next to lead } \\
\text { recycling plant }\end{array}$ & $\begin{array}{c}\text { Reference factory } \\
20 \mathrm{~km} \text { distant }\end{array}$ \\
\hline No. & 36 & 47 \\
Age (years) & $33.0 \pm 9.6$ & $35.1 \pm 11.5$ \\
Duration of work (years) & $3.0 \pm 1.7$ & $6.7 \pm 5.4$ \\
\% Male & 83.3 & 74.5 \\
$\%$ Male smoker & 43 & 57 \\
\hline
\end{tabular}

TABLE III. Comparison of Initial Blood Lead Levels $(\mu \mathrm{g} / \mathrm{dl})$ of Workers in the Two Iron Forging Factories by Wilcoxon Rank Sum Test.

\begin{tabular}{|c|c|c|c|c|c|c|}
\hline & \multicolumn{3}{|c|}{ Exposed factory } & \multicolumn{3}{|c|}{ Reference factory } \\
\hline & $\begin{array}{l}\text { No. of } \\
\text { workers }\end{array}$ & Median & Range & $\begin{array}{c}\text { No. of } \\
\text { workers }\end{array}$ & Median & Range \\
\hline Working indoors (total) & 11 & $11^{\mathrm{a}, \mathrm{b}}$ & $21 \sim 6$ & 11 & $5^{\mathrm{c}}$ & $5 \sim 4$ \\
\hline Male & 6 & 15 & $21 \sim 6$ & 4 & 5 & $5 \sim 4$ \\
\hline Female & 5 & 11 & $14 \sim 9$ & 7 & 4 & $5 \sim 4$ \\
\hline Working outdoors (total) & 25 & $24^{\mathrm{a}}$ & $49-10$ & 36 & 5.5 & $20-4$ \\
\hline Male & 24 & 23 & $49 \sim 10$ & 31 & 6 & $20 \sim 4$ \\
\hline Female & 1 & 40 & & 5 & 4 & $5-4$ \\
\hline New employees or truck drivers & 5 & $8^{\mathrm{d}}$ & $14 \sim 3$ & 4 & 6 & $9 \sim 5$ \\
\hline
\end{tabular}

${ }^{a} p<0.001$, if compared with the reference factory.

${ }^{\mathrm{b}} \mathrm{p}<0.001$, if compared with working outdoors.

${ }^{c} p>0.1$, if compared with working outdoors and stratified by sex.

${ }_{\mathrm{d}} \mathrm{p}=0.003$, if compared with workers employed for more than 2 months by the same factory.

TABLE IV. Results of Multiple Linear Regression Analysis of Blood Lead Levels of All Examined Forging Plant Workers*

\begin{tabular}{lcr}
\hline Variable definition & $\begin{array}{c}\text { Regression } \\
\text { coefficient } \pm \mathrm{SE}\end{array}$ & $\mathrm{p}$ value \\
\hline Intercept & 5.34 & \\
$\begin{array}{l}\text { Exposed factory, indoors } \\
\quad \text { Yes }=1, \text { no }=0\end{array}$ & $6.84 \pm 1.96$ & $<0.00 \mathrm{I}$ \\
$\begin{array}{l}\text { Exposed factory, outdoors } \\
\quad \text { Yes }=1, \text { no }=0\end{array}$ & $17.6 \pm 1.45$ & $<0.001$ \\
$\begin{array}{l}\text { Smoking in plant } \\
\quad \text { Yes }=1, \text { no }=0\end{array}$ & $-0.73 \pm 1.40$ & 0.61 \\
Sex & & \\
$\quad$ Male $=1$, female $=0$ & $1.13 \pm 1.74$ & 0.52 \\
\hline *Multiple $\mathrm{R}^{2}=0.68$. & &
\end{tabular}

part-time job or a lead-related hobby. Moreover, none of their family members currently held a lead-related job.

Five months after improvements in pollution control and decrease in production volume at the nearby lead factory, 30 of the exposed workers were retested for blood lead. The blood lead of outdoor workers had an average decrease of $4.2 \mu \mathrm{g} / \mathrm{dl}$, while 
TABLE V. Results of Paired $t$ Test of Blood Lead Levels $(\mathrm{PbB}$, in $\mu \mathrm{g} / \mathrm{dl})$ at First Examination and 5 Months Later Among Workers at a Forging Plant Adjacent to a Battery Recycling Plant

\begin{tabular}{lrcccc} 
& & \multicolumn{5}{c}{ PbB difference } \\
\cline { 3 - 6 } Working & No. & Mean \pm 1 SD & Maximum & Minimum & p value \\
\hline Indoors & 9 & $0.9 \pm 0.7$ & 4 & -2 & 0.24 \\
Outdoors & 21 & $4.2 \pm 1.4$ & 26 & -3 & 0.008 \\
\hline
\end{tabular}

that of indoor workers showed no significant difference (Table V). Multiple linear regression analysis also showed that sex, smoking, and working outdoors per se all did not have any significant effect on the self-comparison difference of blood lead between two examinations.

\section{DISCUSSION}

We have observed that blood lead levels among workers exposed to lead emissions from an adjacent factory were higher than those of reference workers. Potential alternative lead sources, such as household activities or transportation did not affect blood lead, and therefore, we believe that exposure at their worksite was the major source of lead exposure. Further evidence supports the hypothesis that the major lead contamination at the exposed factory was fugitive dust emitted by the neighboring lead battery recycling plant.

Firstly, blood lead levels among workers of the exposed factory who were employed less than 2 months were lower than those employed longer, but a similar comparison inside the reference factory showed no difference. Secondly, our previous study showed that there was lead contamination around the lead recycling plant. Also, at the same period of this study, air concentrations of lead monitored by the local environmental protection bureau showed a range of $14-32 \mu \mathrm{g} / \mathrm{m}^{3}$. Thirdly, all workers at the exposed factory took lunch, which was supplied by the company, in the plant and they drank from the same source of water. So, the difference in blood leads between indoor and outdoor workers could not be attributed to food or water at the workplace. Fourthly, both factories denied that their raw materials contain lead or its alloy. In the forging process, metal is heated to $1,000^{\circ} \mathrm{C}$ and there is an exposure of metal fume. However, the 11 workers at the exposed factory who engaged in forging did not show a higher blood lead than the other outdoor workers. So, the forging operation was not a major source of lead exposure in our study. Fifthly, indoor workers at the exposed factory had an elevated blood lead compared with indoor workers of the reference factory. And, the blood lead levels among outdoor workers at the exposed factory were higher than those working indoors. Such difference was not affected by sex or social class. Lastly, 5 months after the production of the battery recycling factory was forced to slow down, all outdoor workers at the exposed factory showed a significant decrease of blood lead. We therefore conclude that the increased blood lead levels of workers at the exposed factory were mainly due to fugitive lead dust contamination from the neighboring battery recycling plant.

Because the operation of the lead recycling plant was not completely stopped, the air monitoring by the local environmental bureau still showed a range of $0.1-9.9$ $\mu \mathrm{g} / \mathrm{m}^{3}, 5$ months after our first worker examinations. Possibly because the soil or dust 
on the ground floor of the exposed forging factory was not removed, we observed a decrease averaging only $4.2 \mu \mathrm{g} / \mathrm{dl}$ among exposed workers, and the Spearman rank correlation coefficient between blood lead levels for the two tests was 0.93 . This finding may indicate that the accumulated bone stores are an endogenous source of lead to blood, in addition to the persistent exposure from a contaminated workplace. These findings emphasize that a comprehensive control of all lead exposure sources is necessary to eliminate such a hazard.

\section{REFERENCES}

Baghurst P, Oldfield R, Wigg N, McMichael A, Robertson E, Vimpani G (1985): Some characteristics and correlates of blood lead in early childhood: Preliminary results from the Port Pirie study. Environ Res 38:24-30.

Baker EL, Folland DS, Taylor TA, Frank M, Peterson W, Lovejoy G (1977): Lead poisoning in children of lead workers: Home contamination with industrial dust. N Engl J Med 296:260-261 .

De la Burde B, Choate MS (1972): Does asymptomatic lead exposure in children have latent sequelae? J Pediatr 81:1088-1091.

Freudenberg N, Golub M (1987): Health education, public policy and disease prevention: A case history of the New York City Coalition to End Lead Poisoning. Health Educ Q 14:380-401.

Hamilton A (1943): "Exploring the Dangerous Trades.' Boston: Little Brown.

Jang CS, Wang JD (1989): Research on occupational and environmental diseases in a battery recycling smelter in Taiwan. [Thesis] National Taiwan University.

Kaye WE, Novotny TE, Tucker M (1987): New ceramics-related industry implicated in elevated blood lead levels in children. Arch Environ Health 42:161-164.

Lippmann M (1990): Lead and human health: Background and recent findings (review) 1989 Alice Hamilton Lecture. Environ Res 51:1-24

Morse DL, Landrigan PJ, Rosenblum BF, Hubert JS, Housworth J (1979): El Paso revisited: Epidemiologic follow-up of an environmental lead problem. JAMA 242:739-741.

Rabinowitz MB, Wang JD, Soong WT (1992): Apparent threshold of lead's effect on child intelligence. Bull Environ Contam Toxicol 48:688-695.

Rutter M (1983): Low level lead exposure: Sources and effects and implications. In Rutter M, Jones RR (eds): "Lead versus Health." New York: John Wiley and Sons, pp 333-370.

Soong WT, Tan KL, Chen RC, Hung TP, Wang CH (1976): Lead encephalopathy in adults: A clinical report of two cases. Bull Chinese Soc Neurol Psychiatry 2:52-56.

Tola S, Nordman CH (1977): Smoking and blood lead concentrations in lead-exposed workers and an unexposed population. Environ Res 13:250-255.

Vimpani G, McMichael A, Robertson E, Wigg N (1985): The Port Pirie study: A prospective study of pregnancy outcome and early childhood growth and development in a lead exposed communityprotocol and status report. Environ Res 38:19-23.

Wang JD, Jang CS, Hwang YH, Chen ZS (1992): Lead contamination around a kindergarten near a battery recycling plant. Bull Environ Contam Toxicol 49:23-30.

Wang JD, Shy WY, Chen JS, Yang KH (1989): Parental occupational lead exposure and lead concentration of newborn cord blood. Am J Ind Med 15:111-115.

Yip PK, Chang YC, Wang JD, Tsasi SY, Chen JS (1988): A small outbreak of lead neuropathy in a tile factory. J Formosan Med Assoc 87:60-65.

Zielhuis RL (1983): Lead alloys and inorganic compound. In Parmeggiani L (ed): "Encyclopaedia of Occupational Health and Safety." Geneva:ILO, pp 1200-1205. 